\title{
Prospective clinical assessment of tibial tuberosity advancement for the treatment of cranial cruciate ligament rupture in dogs $^{1}$
}

Luciano Pereira de Barros', Laura Raquel Rios Ribeiro', Letícia Cordeiro de Pina Camondá Pereira", Fernando Lucas Maschio Ferreira'", Maria Eduarda Bastos Andrade Moutinho da Conceição'v, Luis Gustavo Gosuen Gonçalves Dias ${ }^{2}$

'MSc DMV, Full Professor, Universidade Católica Dom Bosco (UCDB), Campo Grande-MS, Brazil. Scientific, intellectual, conception and design of the study; acquisition of data; technical procedures.

"DMV, Veterinary Medicine, Campo Grande-MS, Brazil. Analysis and interpretation of data, statistical analysis.

"'Graduate student, Veterinary Medicine, UCDB, Campo Grande-MS, Brazil. Scientific, intellectual, conception and design of the study; acquisition of data; technical procedures.

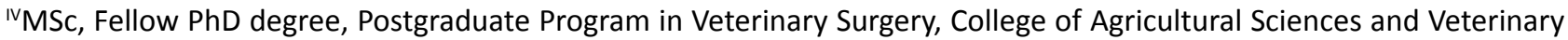
Medicine, Universidade Estadual Paulista (UNESP), Jaboticabal-SP, Brazil. Analysis and interpretation of data, manuscript preparation and writing.

'PhD, Assistant Professor, Veterinary Medicine, College of Agricultural Sciences and Veterinary Medicine, UNESP, Jaboticabal-SP, Brazil. Analysis and interpretation of data, manuscript preparation.

\footnotetext{
Abstract

Purpose: To evaluate clinically dogs that underwent tibial tuberosity advancement (TTA) six months previously.

Methods: Dogs of various breeds, gender, weight, and age that had CCL rupture and underwent TTA for treatment were included in this study. Parapatellar arthrotomy was performed in all patients to assess the joint for a ruptured ligament and meniscal injury before the TTA. The appropriate cage for the TTA was chosen with planning surgery. The surgical procedure was performed according to the literature, using a modified Maquet technique. Six months after surgery, lameness during walking; muscular atrophy; crepitation, cranial drawer and tibial compression tests and quality of life based on owner's evaluation were assessed.

Results: Postoperative complications were observed in only one knee (4.76\%), with a surgical site seroma. The mean lameness score at walking was $0.29( \pm 0.64)$. The mean score regarding muscular atrophy was $0.95( \pm 1.56)$. The mean score of the cranial drawer test, in a range from 0 to 5 , was 1.52 ( \pm 1.54 ). The owners rated the dog's quality of life as excellent in $44 \%$, good in $30 \%$, and moderate in $17 \%$.

Conclusion: This clinical study supports the affirmation that patients who undergo TTA for treatment of CCL rupture have an acceptable response.

Key words: Orthopedics. Osteotomy. Veterinary. Dogs.
} 


\section{Introduction}

The role of the cranial cruciate ligament $(C C L)$ is to prevent cranial movement of the tibia relative to the femur, internal rotation of the tibia, and hyperextension of the knee ${ }^{1}$. In dogs, CCL rupture has multiple causes, involving genetics, conformation, and inflammatory changes, that combine to promote an imbalance between biomechanics applied to the CCL and its capacity to support the load. Thus, degeneration and rupture of the ligament can occur leading to instability of the stifle joint ${ }^{2,3}$.

Multiple surgical techniques have been described to treat CCL rupture, although none are ideal, because they all allow for progression of stifle osteoarthritis (OA $)^{4-6}$. OA occurs due to the inaccuracy of the techniques, which allow for movement of the joint ${ }^{7}$.

Among the techniques, proximal tibial osteotomies alter the stifle geometry and cause dynamic stability that nullifies the force of cranial translation of the tibia, which decreases the progression of $\mathrm{OA}^{1,8-10}$.

Tepic et al. ${ }^{1}$ presented a biomechanical theory describing the results when the force on the stifle joint is parallel to the patellar ligament. Thus, the tibial cranial translation is performed in reference to the angle between the tibial plateau and the patellar ligament. When the patellar ligament is perpendicular to the tibial plateau, the resulting force on the joint is minimal. This can be achieved with a tibial tuberosity advancement (TTA $)^{5,11}$.

The aim of the present study was to clinically assess dogs that underwent TTA six months previously. Orthopedic examination, including lameness score (range $0-4)^{16}$, muscle atrophy, crepitation on manipulation, cranial drawer, and tibial compression test, were assessed.

\section{Methods}

This work was submitted and approval by Animal Ethic and Use Committee, Universidade Estadual Paulista, protocol number 008038/18.

Dogs of various breeds, gender, weight, and age admitted at veterinary hospital of Universidade Católica Dom Bosco, Campo Grande-MS, Brazil, that had CCL rupture and underwent TTA for treatment were included in this study. The diagnosis was made by cranial drawer and tibial compression tests. Complete orthopedic examination and radiography were performed to evaluate for the presence of joint effusion or OA. Dogs with contralateral $\mathrm{CCL}$ rupture were not excluded from the study.

Fasting of solids and liquids were started at 8 and $2 \mathrm{~h}$ prior to surgery, respectively. A combination of acepromazine (0.03 $\mathrm{mg} / \mathrm{kg}$ ) and tramadol (1 $\mathrm{mg} / \mathrm{kg}$ ) was injected intramuscularly as a pre-anesthetic, and anesthesia was induced with propofol (5 $\mathrm{mg} / \mathrm{kg} \mathrm{IV).} \mathrm{Animals} \mathrm{were} \mathrm{intubated} \mathrm{with}$ an endotracheal tube, and anesthesia was maintained with $0.5 \%$ isoflurane vaporized in $100 \%$ oxygen in a closed circuit. Furthermore, epidural anesthesia with morphine $(0.1 \mathrm{mg} / \mathrm{kg})$ and lidocaine $(0.5 \mathrm{mg} / \mathrm{kg})$ was performed.

Parapatellar arthrotomy was performed in all patients to assess the joint for a ruptured ligament and meniscal injury before the TTA. The ruptured ligament and injured meniscus were removed. Meniscal release was not performed if the meniscus was normal.

The appropriate cage for the TTA was chosen with planning surgery, using software and a mediolateral radiograph with the knee angled at 135․ The surgical procedure was performed according to the literature with titanium cage ${ }^{12-14}$, using a modified Maquet technique ${ }^{15}$.

Oral cephalexin $(30 \mathrm{mg} / \mathrm{kg}$, every $12 \mathrm{~h}$, for 10 days), tramadol ( $2 \mathrm{mg} / \mathrm{kg}$, every $12 \mathrm{~h}$, for 7 days), and meloxicam $(0.1 \mathrm{mg} / \mathrm{kg}$, every $24 \mathrm{~h}$, for 5 days), in addition, movement restriction for 4 to 8 weeks, were prescribed. 
Six months after surgery, assessment was performed regarding the following criteria: lameness during walking; muscular atrophy; crepitation, ranging from $0-4$, as described by Hudson et al. ${ }^{16}$; cranial drawer and tibial compression tests, ranging from 0-5, as described by Hudson et al. ${ }^{16}$; and quality of life based on owner's evaluation, ranging from 9 to 36 , with 9 to $15=$ terrible, 16 to $22=$ bad, 23 to $29=$ moderate, 30 to $33=$ good, and 34 to $36=$ excellent.

\section{Results}

Eighteen dogs (eight males and ten females) were included in the study, and three of the dogs had contralateral rupture. Therefore, a total of 21 operated knees (11 left and 10 right) were evaluated. Mean age of the patients was 7.4 years $( \pm 3.5)$, and mean weight was $20.39 \mathrm{~kg}( \pm 13.5)$.

Postoperative complications were observed in only one knee $(4.76 \%)$, with a surgical site seroma. The knee was treated with draining of the fluid, daily cleaning, and bandaging.

Six months postoperatively, no lameness at running was observed in $81 \%$ of the dogs. The mean lameness score at walking was $0.29( \pm 0.64)$. Muscular atrophy was not observed in $62 \%(13 / 21)$, while mild atrophy was observed in $19 \%(4 / 21)$, and moderate in $19 \%(4 / 21)$. The mean score and standard deviation regarding muscular atrophy were 0.95 ( \pm 1.56$)$.

No crepitation was palpated on eight (38\%) of the knees, while four (29\%) had mild crepitation, seven (33\%) moderate, and two (10\%) high. The mean score and standard deviation, in a range from 0 to 4, were 1.14 ( \pm 1.06 ).

Regarding the tibial compression test, $57 \%(12 / 21)$ were negative, $38 \%$ (8/21) partially positive, and $5 \%(1 / 21)$ positive. For the cranial drawer test, $43 \%$ were negative, $38 \%$ partially positive, and $19 \%$ positive. The mean score and standard deviation of the cranial drawer test, in a range from 0 to 5 , was $1.52( \pm 1.54)$.

The quality of life evaluation was performed by all owners. In dogs that had both knees operated on, the questionnaire was completed after the second surgery, and they had the same answers for both knees. The results of the questionnaire are shown in Table 1. Regarding lameness, $52.3 \%$ of dogs had no signs six months postoperatively. The owners rated the dog's quality of life as excellent (score from 34 to 36 ) in 44\%, good (score from 30 to 33 ) in 30\%, and moderate (score from 23 to 29 ) in $17 \%$. No patient's quality of life was classified as bad or terrible.

Table 1 - Questions regarding quality of life of the dogs, evaluated by the owners.

\begin{tabular}{|c|c|c|c|}
\hline Question & Bad & Good & Excellent \\
\hline 1. Did the surgery disturb the dog's life? & $0 \%$ & $5 \%$ & $95 \%$ \\
\hline 2. Does the dog show lameness on the operated limb? & $0 \%$ & $48 \%$ & $52 \%$ \\
\hline 3. Is he/she eating? & $0 \%$ & $5 \%$ & $95 \%$ \\
\hline 4. Is he/she unusually tired? & $38 \%$ & $10 \%$ & $50 \%$ \\
\hline 5. Is he/she still playing as before? & $0 \%$ & $14 \%$ & $86 \%$ \\
\hline 6. How is he sleeping? & $5 \%$ & $24 \%$ & $71 \%$ \\
\hline 7. Can your dog position to urinate and defecate normally? & $0 \%$ & $0 \%$ & $100 \%$ \\
\hline 8. How is his/her behavior? & $0 \%$ & $5 \%$ & $95 \%$ \\
\hline 9. Is he/she licking the operated limb? & $10 \%$ & $0 \%$ & $90 \%$ \\
\hline
\end{tabular}




\section{- Discussion}

Approximately $48 \%$ of dogs with $\mathrm{CCL}$ rupture will experience rupture in the contralateral limb ${ }^{17}$. However, in the present study, only three $(16.7 \%)$ of the dogs had CCL rupture in the other limb. This could be due to the evaluation time of only six months after surgery. More patients may have developed contralateral rupture after the follow-up evaluation. Medeiros et al. ${ }^{5}$, who evaluated dogs four months postoperatively, found $\mathrm{CCL}$ rupture in the contralateral limb in 7 (20\%) out of 35 dogs, similar to the percentage found in this study.

The low rate of postoperative complications observed in this study was different from others that have reported rates of 11 to $59 \%$ for minor and major complications, such as meniscal injury, tibial fracture, infection, granuloma, fracture or loosening of the screws, implant rejection, septic arthritis, and patellar luxation ${ }^{5,13,14}$. In the present study, all of the surgeries were performed with aseptic technique by an expert surgeon, which could decrease complications.

The lameness rates at gait analysis after TTA in literature are divergent; one study showed that $68 \%$ of all patients had no lameness four months after surgery ${ }^{14}$. In another study using Ricinus communis polyurethane polymer as the cage in a modified TTA, Medeiros et $a l .{ }^{5}$ had an excellent result, with $95 \%$ of dogs showing minimal or no lameness at four months postoperatively. In our study, the recovery rate was $81 \%$, similar to that showed by Lafaver et al. $^{13}(74.5 \%)$. The difference among these results can be explained by the difference in clinic observers, since it is a subjective analysis. Thus, the assessment duration is important, as affirmed by Mölsä et al. ${ }^{18}$ since in veterinary medicine follow-up is often limited to one reassessment.

In this study, $62 \%$ of the dogs had no muscular atrophy. This is different from the results of a study that promoted iatrogenic rupture of the $\mathrm{CCL}$ and early treatment, which showed evident muscular atrophy at two weeks and progression until five weeks postoperatively, and few recovered the muscular mass after ten weeks ${ }^{19}$.

In this study, $38 \%$ of patients had no crepitation on palpation, $29 \%$ had mild crepitation, 33\% moderate, and 10\% high. Crepitation occurs due to the presence of osteophytes in the joint from OA. Medeiros et al. ${ }^{7}$, observed radiographic signs of OA mainly at five years after modified TTA.

Other techniques used to treat $\mathrm{CCL}$ rupture also allow some movement in the knee. Therefore, there is no technique that completely nullifies the joint instability observed after CCL rupture and prevents $O A$ development, as well as the resultant joint crepitation, pain, and lameness ${ }^{4,20-22}$.

Bruce et al..$^{23}$ observed that $89 \%(57 / 64)$ of stifles were positive on the tibial compression test 6 to 12 weeks after triple tibial osteotomy, and this rate increased to $91 \%(50 / 55)$ after 11 to 26 weeks. Similarly, Medeiros et al. ${ }^{7}$ affirmed that all of the operated knees were positive after modified TTA. However in our study, only $5 \%$ of patients were positive on the tibial compression test, $38 \%$ partially positive, and $57 \%$ were negative, and no dogs showed pain.

Osteotomies for treatment of $\mathrm{CCL}$ rupture promote dynamic stability; thus, cranial compression test, which mimics stepping, should be negative after surgery. However, our hypothesis was that because of the inaccuracy of all techniques, they allow instability. Au et al. ${ }^{4}$, corroborated this hypothesis in an ex vivo biomechanics study in dogs, as they observed that after tibial plateau leveling osteotomy (TPLO), there was cranial tibial translation. Additionally, Bruce et al. ${ }^{23}$ affirmed that the cranial tibial test is not similar to forces in the knee during walking, because once load is applied on the joint through loading mechanism of the calcaneus tendon, the dynamic stability of the knee depends on 
various muscle contractions.

The results obtained in the questionnaire (Table 1) were similar to those observed by other authors, who showed that more than $90 \%$ of owners classified their dog's gait as good or excellent after surgery ${ }^{7,18}$.

Bruce et al. ${ }^{23}$ established that $100 \%$ of owners reported an increase in quality of life of patients 12 months after triple tibial osteotomy, and Dymond et al. ${ }^{24}$ affirmed that $87 \%$ of owners reported good recovering 13 months postoperatively after TTA. All owners in both studies said that they would opt for the same procedure in similar cases. In another study, Hoffman et al. ${ }^{12}$ showed that $75 \%$ of owners classified their dog's quality of life as excellent 24 months after TTA.

Despite the fact that we noted lameness, crepitation, and positive cranial compression test in various dogs, most of the owners reported being satisfied after TTA treatment of $\mathrm{CCL}$ rupture. This is likely because the owners do not see the changes observed by trained veterinarians, and the dog's quality of life increases after surgery.

\section{Conclusion}

Patients who undergo tibial tuberosity advancement for treatment of cranial cruciate ligament rupture have an acceptable response regarding gait, muscular atrophy, crepitation, cranial drawer, and tibial compression tests.

\section{References}

1. Tepic S, Damur DM, Montavo PM. Biomechanics of the stifle joint. 1st World Orthopaedic Veterinary Congress. Munich, Germany; 2002.

2. Comerford EJ, Smith K, Hayashi K. Update on the aetiopathogenesis of canine cranial cruciate ligament disease. Vet Comp Orthop Traumatol. 2011;24(4):91-8. doi: 10.3415/ VCOT-10-04-0055.

3. Griffon DJ. A review of the pathogenesis of canine cranial cruciate ligament disease as a Basis for future preventive strategies. Vet
Surg. 2010;39(4):399-409. doi: 10.3415/ VCOT-10-04-0055.

4. Au KK, Gordon-Evans WJ, Dunning D, O'DellAnderson KJ, Knap KE, Griffon D, Johnson AL. Comparison of short- and long-term function and radiographic osteoarthrosis in dogs after postoperative physical rehabilitation and tibial plateau leveling osteotomy or lateral fabellar suture stabilization. Vet Surg. 2010;39:173-80. doi: 10.1111/j.1532950X.2009.00628.x.

5. Medeiros RM, Silva MAM, Teixeira PPM, Dias LGGG, Chung DG, Zani CC, Feliciano, MAR, Conceição MEBAM, Machado MRF, Rocha AG, Chierice GO, Coutinho LN, Padilha Filho JG. Use of castor bean polymer in developing a new technique for tibial tuberosity advancement for cranial cruciate ligament rupture correction in dogs. Vet Med (Praha). 2016;61(7):382-8. doi: 10.17221/168/2015-VETMED.

6. Moeller EM, Allen DA, Wilson ER, Lineberger $J A$, Lehenbauer T. Long-term outcomes of thigh circumference, stifle range-of-motion, and lameness after unilateral tibial plateau leveling osteotomy. Vet Compar Orthop Traumatol. 2010;1:37-42. doi: 10.3415/ VCOT-09-04-0043.

7. Medeiros RM, Silva MAM, Teixeira PPM, Chung DG, Conceição MEBAM, Chierice GO, Padilha filho JG, Dias LGGG. Long-term assessment of a modified tibial tuberosity advancement technique in dogs. Arq Bras Med Vet Zootec. 2018;70(4). doi: 10.1590/1678-4162-9594.

8. Kim SE, Pozzzi A, Banks SA, Conrad BP, Lewis DD. Effect of tibial tuberosity advancement on femorotibial contact mechanics and stifle kinematics. Vet Surg. 2009;38:33-9. doi: 10.1111/j.1532-950X.2008.00471.x.

9. Lazar TP, Berry CR, Dehaan JJ, Peck JN, Correa M. Long-term radiographic comparison of tibial plateau leveling osteotomy versus extracapsular stabilization for cranial cruciate ligament rupture in the dog. Vet Surg. 2005;34:133-41. doi: 10.1111/j.1532950X.2005.00021.x.

10.Montavon PM, Damur D, Tepic S. Tibial tuberosity advancement (TTA) for the treatment of cranial cruciate disease in dogs: evidences, technique and initial clinical results. 12th ESVOT Congress. Munich, Germany; 2004.

11.Samoy Y, Verhoeven G, Bosmans T, van der Vekens $E$, de Bakker E, Verleyen P, van Ryssen 
B. TTA Rapid: description of the technique and short term clinical trial results of the first 50 cases. Vet Surg. 2014;43(7):1-11. doi: 10.1111/j.1532-950X.2014.12298.x.

12. Hoffman DE, Miller JM, Ober CP, Lanz OI, Martin RA, Shires PK. Tibial tuberosity advancement in 65 canine stifles. Vet Comp Orthop Traumatol. 2006;19:219-27. PMID: 17143394.

13.Lafaver S, Miller NA, Stubbs WP, Taylor RA, Boudrieau RJ. Tibial tuberosity advancement for stabilization of the canine cranial cruciate ligament-deficient stifle joint: Surgical technique, early results, and complications in 101 dogs. Vet Surg. 2007;36:573-86. doi: 10.1111/j.1532-950X.2007.00307.x.

14. Macdonald TS, Allen DA, Monteith GJ. Clinical assessment following tibial tuberosity advancement in 28 stifles at 6 months and 1 year after surgery. Can Vet J. 2013 Mar;54(3):249-54. PMID: 23997261.

15. Brunel L, Etchepareborde S, Barthélémy N, Farnir F, Balligand M. Mechanical testing of a new osteotomy design for tibial tuberosity advancement using the Modified Maquet Technique. Vet Comp Orthop Traumatol. 2013;26:47-53. doi: 10.3415/VCOT-11-12-0176.

16. Hudson J, Slater MR, Taylor L, Scott HM, Kerwin SC. Assessing repeatability and validity of a visual analogue scale questionaire for use in assessing pain and lameness in dogs. Am J Vet Res. 2004;65(2):1634-43. PMID: 15631027.

17. Buote N, Fusco J, Radasch R. Age, tibial plateau angle, sex, and weight as risk factors for contralateral rupture of the cranial cruciate ligament in labradors. Vet Surg. 2009;38:481-9. doi: 10.1111/j.1532950X.2009.00532.x.

18.Molsa SH, Hielm-Björkman AK, LaitinenVapaavuori OM. Use of an owner questionnaire to evaluate long-term surgical outcome and chronic pain after cranial cruciate ligament repair in dogs: 253 cases (2004-2006). J Am Vet Med Assoc. 2013;243(5):689-95. doi: 10.2460/javma.243.5.689.

19. Millis DL, Levine D, Mynatt T. Changes in muscle mass following transection of the cranial cruciate ligament and immediate stifle stabilization. Proceedings of the First International Symposium on Rehabilitation and Physical Therapy in Veterinary Medicine, Oregon State University. August 7-11, 1999:155.

20. Hurley, CR, Hammer DL, Shott S. Progression of radiographic evidence of osteoarthritis following tibial plateau leveling osteotomy in dogs with cranial cruciate ligament rupture: 295 cases (2001-2005). J Am Vet Med Assoc. 2007;230:1674-9. doi: 10.2460/ javma.230.11.1674.

21.Johnson K, Lanz O, Elder S, Mclaughlin $R$, Were $S$, Hasper T. The effect of stifle angle on cranial tibial translation following tibial plateau leveling osteotomy: an in vitro experimental analysis. Can Vet J. 2011;52:961-6. PMID: 22379194.

22. Knight RC, Thomson DG, Danielski A. Surgical management of pivot-shift phenomenon in a dog. J Am Vet Med Assoc. 2017;250(6):67680. doi: 10.2460/javma.250.6.676.

23. Bruce WJ, Rose A, Tuke J, Robins GM. Evaluation of the Triple Tibial Osteotomy (TTO): a new technique for the management of the cranial cruciate-deficient stifle. Vet Comp Orthop Traumatol. 2007;20:159-68. PMID: 17846680.

24.Dymond NL, Goldsmid SE, Simpson DJ. Tibial tuberosity advancement in 92 canine stifles: initial results, clinical outcome and owner evaluation. Aust Vet J. 2010;88:381-5. doi: 10.1111/j.1751-0813.2010.00627.x.

\section{Correspondence:}

Luis Gustavo Gosuen Gonçalves Dias

Via de acesso Paulo Donatto Castelane, $s / n$

CEP: 14884-900 Jaboticabal - SP Brasil

Tel.: (55 16)98257-9040

gustavogosuen@gmail.com

Received: Apr 12, 2018

Review: June 13, 2018

Accepted: July 15, 2018
Conflict of interest: none

Financial source: none
${ }^{1}$ Research performed at Veterinary Hospital, Universidade Católica Dom Bosco (UCDB), Campo Grande-MS, Brazil. 